\title{
Influence of the Natural Zeolite Particle Size Toward the Ammonia Adsorption Activity in Ceramic Hollow Fiber Membrane
}

\author{
Mohd Ridhwan Adam ${ }^{1}$, Mohd Hafiz Dzarfan Othman ${ }^{1, *}$, \\ Siti Hamimah Sheikh Abdul Kadir ${ }^{2, *}{ }^{\mathbb{C}}$, Mohd Nazri Mohd Sokri ${ }^{1} \oplus$, Zhong Sheng Tai ${ }^{1}$, \\ Yuji Iwamoto ${ }^{3}$ D , Masaki Tanemura ${ }^{4}$, Sawao Honda ${ }^{3}$, Mohd Hafiz Puteh ${ }^{5}$, \\ Mukhlis A. Rahman ${ }^{1}$ and Juhana Jaafar ${ }^{1}$ \\ 1 Advanced Membrane Technology Research Centre (AMTEC), School of Chemical and Energy \\ Engineering (SCEE), Faculty of Engineering, Universiti Teknologi Malaysia, UTM, Skudai, Johor 81310, \\ Malaysia; ridhwan_adam@yahoo.com (M.R.A.); nazri@petroleum.utm.my (M.N.M.S.); \\ taizhongsheng92@gmail.com (Z.S.T.); mukhlis@petroleum.utm.my (M.A.R.); \\ juhana@petroleum.utm.my (J.J.) \\ 2 Institute of Medical Molecular Biotechnology, Faculty of Medicine, Sungai Buloh Campus, \\ Universiti Teknologi MARA (UiTM), Jalan Hospital, Sungai Buloh, Selangor 47000, Malaysia \\ 3 Department of Environmental and Materials Engineering, Nagoya Institute of Technology, Gakiso-cho, \\ Showa-ku, Nagoya 466-8555, Japan; iwamoto.yuji@nitech.ac.jp (Y.I.); honda@nitech.ac.jp (S.H.) \\ 4 Department of Physical Science and Engineering, Nagoya Institute of Technology, Gakiso-cho, Showa-ku, \\ Nagoya 466-8555, Japan; tanemura@system.nitech.ac.jp \\ 5 Department of Environment, School of Civil Engineering (SCE), Faculty of Engineering, \\ Universiti Teknologi Malaysia, UTM, Skudai, Johor 81310, Malaysia; mhafizputeh@utm.my \\ * Correspondence: hafiz@petroleum.utm.my (M.H.D.O.); sitih587@salam.uitm.edu.my (S.H.S.A.K.)
}

Received: 24 February 2020; Accepted: 26 March 2020; Published: 4 April 2020

check for updates

\begin{abstract}
Natural zeolite is widely used in removing ammonia via adsorption process because of its superior ion-exchange properties. Ceramic particle size affects the adsorptivity of particles toward ammonia. In this study, hollow fiber ceramic membrane (HFCM) was fabricated from natural zeolite via phase inversion. The effect of natural zeolite particle size toward the properties and performance of HFCM was evaluated. The results show that the HFCM with smaller particle sizes exhibited a more compact morphological structure with better mechanical strength. The adsorption performance of HFCM was significantly improved with smaller particle sizes because of longer residence time, as proven by the lower water permeability. A high adsorption performance of $96.67 \%$ was achieved for HFCM with the smallest particle size $(36 \mu \mathrm{m})$. These findings provide a new perspective on the promising properties of the natural zeolite-derived HFCM for ammonia removal.
\end{abstract}

Keywords: natural zeolite; adsorptive ceramic membrane; phase inversion; particle size; adsorption

\section{Introduction}

Potable water scarceness has become a crucial problem across the globe for many years. The introduction of many contaminants into water bodies has worsened the effect of water pollution. The presence of contaminants, such as heavy metals, toxic chemicals, and industrial wastes, is known as one of the foremost causes of this problem [1]. The rapid growth of industrialization, along with the increasing human population, has brought a massive impact on drinkable water demand. Thus, the necessity to treat wastewater for a sustainable potable water source is an inevitable challenge [2]. The present water purification and wastewater treatment are no longer adequate to meet the needs of the future generation. 
Ammonia is one of the known water pollutants. It is a common contaminant in both municipal and industrial wastewaters. The growth in industrial processes specifically in coking, coal gasification, and petroleum refining; and industrial productions of chemical fertilizers, pharmaceuticals, and catalysts; has led to a large production of ammoniacal wastewater [3]. Excessive nitrogen compound in wastewater is a significant pollution burden since it has distinctive characteristics and leads to the depletion of dissolved oxygen required for aquatic life. Moreover, excessive nitrogen compound has toxic effects on fish, lowers disinfection efficiency, and accelerates the corrosion of metals and construction materials [4].

One of the best-known solutions for tackling this issue is the separation and purification of wastewater. This solution requires the implementation of cutting-edge equipment, such as membrane separation technologies. Up to now, membrane technology has been utilized in a broad range of applications to separate individual components from either liquid or gas mixtures. Past studies have shown that membrane technology is applicable for removing ammonia in wastewater in a clean and effective way. This could be ascribed by the high ammonia removal efficiency in addition to the compact design and low energy cost compared to conventional ammonia wastewater treatments such as air-stripping, denitrification, coagulation and flocculation, and biological treatment.

Currently, most of the commercially available membranes in the market are polymeric-based membranes, which are cheaper to produce and have high perm selectivity [5-7]. However, these polymeric membranes are limited to mild operating conditions, specifically low operating temperature and pressure. This could be attributed by their weak thermal stability and ease of fouling [8]. Membrane fouling is a severe problem, and further treatment is needed to ensure excellent membrane performance [9]. Strong hydrophilicity helps in reducing membrane fouling. Therefore, researchers are now focusing on the development of ceramic-based membrane as it has high durability in harsh environments and possesses high hydrophilicity [10]. Additionally, most of the membranes used in treating wastewater containing contaminants such as heavy metals, humic acid, pharmaceutical wastes, and ammonia are mainly of inorganic ceramic materials. These materials possess outstanding durability under high pressure and temperature, great chemical stability, good defouling property, and long-lasting usability [11]. However, the needs of high sintering temperature and expensive starting materials such as alumina, zirconia, and titania have led to the least choice of ceramic materials to be used as membrane [12,13]. As a consequence, there is a necessity to find inexpensive ceramic materials to replace costly ceramics.

There is an eminent need to search for alternative membrane materials. Various studies have been devoted to fabricating the ceramic membranes using minerals and waste materials such as clay, fly ash, bauxite, and kaolin [14-16]. However, these materials can be costly, are less effective for ammonia adsorption, and possess inconsistency potentially due to different batches of the waste [17]. For example, bauxite contains a high amount of alumina; thus, it requires high sintering temperature to be produced as a ceramic membrane [18]. Meanwhile, the usage of the fly ash may lead to the production of porous materials that contain various phases including mullite, anorthite, and cordierite [19]. The membranes of pure fly ash typically possess low mechanical strength and need additives to enhance their durability [20].

Alternatively, natural zeolite has been studied as an alternative material to be developed as a low-cost ceramic membrane. Natural zeolite is abundantly found around the world as crystalline hydrated aluminosilicates of alkali and earth metals [21]. Dong et al. fabricated a tubular microfiltration membrane for water filtration [22]. Although this approach is interesting, the big configuration of the tubular membrane resulted in low performance because of low surface area [23]. As an alternative, hollow fiber configuration offers several advantages such as large membrane area per unit volume, good mechanical support to withstand liquid separation or backwashing, and easy handling of fabrication and operational processes [24,25]. These properties will improve the separation performance of the fabricated ceramic membrane. Thus, this study evaluated the potential of a natural zeolite (clinoptilolite) as a microfiltration membrane for the removal of ammonia via adsorption. Also, the 
excellent adsorbent and separation properties of this natural zeolite have made it a cheaper ceramic material for membrane fabrication. Additionally, this natural zeolite guarantees promising results in the removal of ammonia in water [26].

To the best of our knowledge, no similar studies have been reported the fabrication of a natural zeolite-based adsorptive hollow fiber ceramic membrane (HFCM) for the removal of ammonia in water. A study was conducted on natural zeolite in HFCM for the removal of chromium(VI) from water [27]. Although the adsorptive membrane produced is similar, the application of the study was limited for the treatment of chromium(VI), and the effect of particle size on the membrane performance was not investigated. Particle size significantly affects membrane properties in terms of mechanical strength, porosity, and water permeability [28]. In addition, a small particle size offers a high surface area, resulting in a large number of active sites [29]. This property eventually increases the adsorptivity of the membrane in ammonia removal. Thus, this work reports the effect of natural zeolite particle size on the physical and chemical properties of the adsorptive HFCM for the treatment of ammonia wastewater. The effects of the ceramic particle size on the physicochemical properties such as membrane compactness, crystallinity of the ceramic, and microtopography of the membrane as well as the performance of the HFCM were studied in detail in this work specifically for the adsorptive removal of ammonia in water treatment. The adsorptive performance is the major concern in this study and the physicochemical properties were also taken into account. The changes in the physical properties of the HFCM eventually affected the membrane performance.

\section{Experimental}

\subsection{Materials}

The materials used for the fabrication of the adsorptive HFCM were natural zeolite (Shijiazhuang Mining Trade Co. Ltd. Ziaoning, China), Arlacel P135 (polyethyleneglycol-30 dipolyhydroxystearate, Uniqema, East Yorkshire, UK) as the dispersant, N-methyl-2-pyrrolidone (NMP, AR grade, QRëC ${ }^{\mathrm{TM}}$, Selangor, Malaysia) as the solvent, and polyethersulfone (PESf, Radal A300, Ameco Performance, Greenville, SC, USA) as the polymer binder. All chemicals were purchased and used without any further purification.

\subsection{Membrane Fabrication and Characterisation}

Natural zeolite with different particle sizes $(36,50$, and $75 \mu \mathrm{m})$ was ground and sieved. The membrane dope suspension was prepared by dissolving Arlacel P135 dispersant into NMP before the addition of pre-dried natural zeolite powder (45 wt \% for each particle size suspension). The suspension was then subjected to ball milling process (NQM-2 planetary ball mill) for $48 \mathrm{~h}$. Then, PESf (5 wt \%) was added into the suspension, and the mixture was further milled for another $48 \mathrm{~h}$. Before the extrusion of the suspension using phase inversion technique, the dope suspension was degassed for $30 \mathrm{~min}$ at room temperature to eliminate the trapped air in the suspension to prevent defect in the pore formation in the membrane structure. After degassing, the spinning suspension was introduced into a syringe pump and extruded through a tube-in-orifice spinneret. Tap water was used as the internal coagulant at $15 \mathrm{~mL} / \mathrm{min}$. The fiber membrane green bodies that passed through a $5 \mathrm{~cm}$ air-gap distance were immersed in a water coagulant bath for $24 \mathrm{~h}$ to allow the completion of the phase inversion process. Afterward, the membrane precursor green bodies were dried at room temperature. Finally, the fiber precursors were sintered in air for $4 \mathrm{~h}$ at $1050{ }^{\circ} \mathrm{C}$, as the best HFCM is obtained when sintered at this temperature [30]. The heating rate was $2{ }^{\circ} \mathrm{C} / \mathrm{min}$ throughout the heating and cooling process of sintering.

The viscosity of the spinning suspension was measured promptly before the spinning process using a viscometer (Brookfield model DV1, Middleboro, MA, USA) at a shear rate range between 1 and $100 \mathrm{~s}^{-1}$ at room temperature. The morphologies of each membrane before and after the surface modification process were examined using scanning electron microscopy (SEM, Hitachi model TM 3000, 
Tokyo, Japan) at different magnifications. Before the SEM analysis, each membrane was coated with gold for 3 min under vacuum. This analysis consisted of both surface and cross-sectional anatomy of the membranes. The microtopography of the natural zeolite and fabricated HFCM was analyzed using transmittance electron microscopy (TEM, JEOL JEM-2100, Tokyo, Japan). The samples were directly mounted on the TEM sample holder without any additional treatment. TEM analysis was performed with a vacuum chamber pressure of less than $2.5 \times 10^{-5} \mathrm{~Pa}$. The crystal phase of the natural zeolite as raw material compared to that of zeolite from HFCM upon the sintering process was analyzed using X-ray diffraction analysis (XRD, Shimadzu model XD-D1, Kyoto, Japan). The mechanical strength of the membrane was measured using a three-point bending machine (Instron model 3342, Norwood, MA, USA). The flexural strength of the membrane was calculated using the following equation:

$$
\sigma F=8 F L D_{o} / \pi\left(D_{o}^{4}-D_{i}^{4}\right)
$$

where $F$ is the maximum load at which the fracture occurred while $L, D_{o}$, and $D_{i}$ are the length of span $(43 \mathrm{~mm})$, the outer diameter, and the inner diameter of the hollow fibers, respectively.

Mercury porosimeter (AutoPore IV, 9500, Micromeritics, Norcross, GA, USA) combined with Micromeritics software (version 1.09) was used to estimate the pore size distribution and overall porosity of the fabricated membranes. Water permeation was measured using a crossflow membrane permeation system, as illustrated in Figure 1. Water permeation flux $\left(F, \mathrm{~L} / \mathrm{m}^{2} \cdot \mathrm{h}\right)$ was calculated using Equation (2) from the measured volume of the permeate $(V, \mathrm{~L})$, membrane area $\left(A, \mathrm{~m}^{2}\right)$, and time $(t, \mathrm{~h})$.

$$
F=\frac{V}{A t}
$$

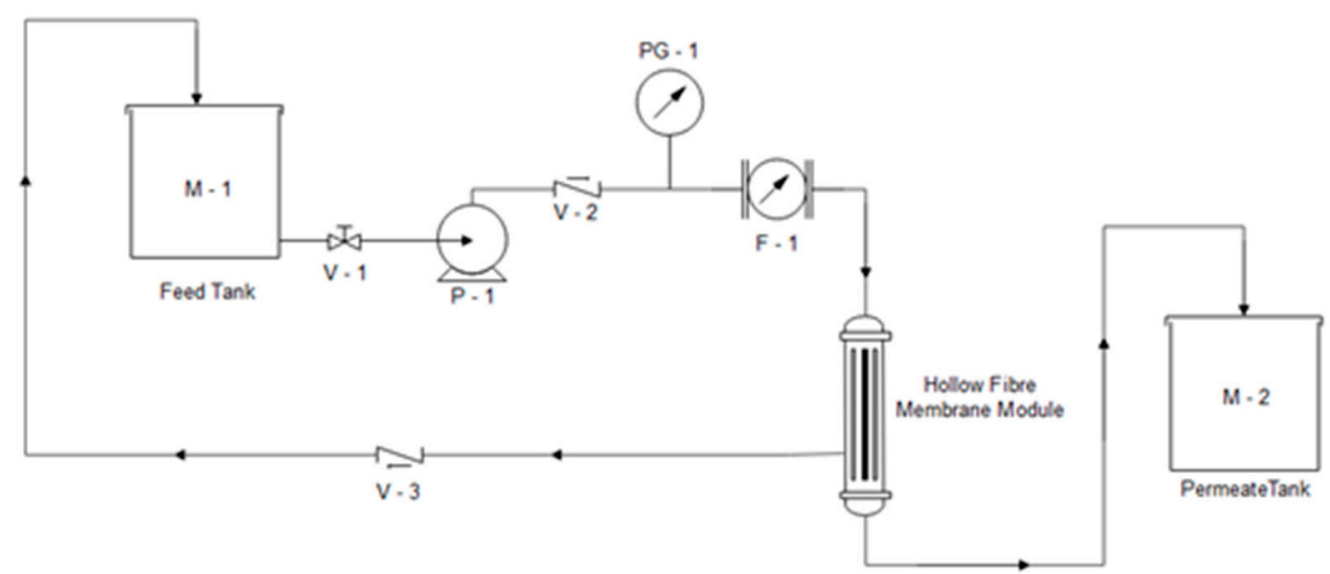

Figure 1. Schematic diagram of the adsorptive hollow fiber ceramic membrane (HFCM) system setup [30].

\subsection{Ammonia Removal by Adsorptive Natural Zeolite HFCM}

The ammonia removal performance of the HFCM via adsorption was evaluated using a dead-end water permeation setup with different grades of synthetic ammonia wastewater. The performance was measured using HFCM of different particle sizes in $50 \mathrm{mg} / \mathrm{L}$ and pH 7 ammonia feed solution. The ammonia contents in both feed and permeate solutions for each analysis were determined using UV-visible spectrophotometry (Hach model DR 5000, Guelph, ON, Canada) with the aid of ammoniacal reagent kit containing ammonium salicylate and ammonium cyanurate as the color indicator for the ammonia content. The color intensities were measured in the mode of absorbance and translated into ammonia content by comparing them to the calibration curve prepared before the spectrophotometric analyses. The ammonia removal performance was calculated using the following equation: 


$$
R=\frac{C_{f}-C_{p}}{C_{f}} \times 100
$$

where $C_{f}$ and $C_{p}$ are the ammonia concentration in the feed and permeate, respectively.

\section{Results and Discussion}

\subsection{Natural Zeolite HFCM Fabrication and Characterisation}

The characterization and the effect of the particle size toward the physicochemical properties of the zeolite adsorptivity on the ammonia were studied in detail. The common analysis of the particle size in adsorption activities is normally reported in the powder suspension form of adsorbent $[29,31]$. The analysis of particle size effect incorporating with the membrane configuration is the novelty of this current work. Although there are studies that report the effect of particle size on membrane technology, they are limited to the particle size of the additive materials embedded in the membrane matrix [32,33]. This current work highlights a new perspective on the effect of particle size on the ceramic membrane adsorption performance.

\subsubsection{Rheology of the Ceramic Suspension}

Viscosity of the dope suspension plays an important role in the determination of the membrane structure. It affects the phase inversion process by controlling the formation of sponge- or finger-like structures in the membrane. Figure 2 depicts the rheology of the zeolite dope suspension prepared using different particle sizes of zeolite powder. The smaller particle size of ceramic led to a highly viscous dope suspension. Thus, the high viscosity led to the formation of the sponge-like structure. In addition, the graph shows the correlation between particle size and viscosity of the dope suspension. The smaller zeolite powder particles dispersed well in the suspension and thus thickened the suspension. A similar trend of findings was reported on the dispersion of nanoparticles of different sizes in a polymeric suspension [34]. Similarly, the increased particle size in this study reduced the specific surface area of the particle, providing a poor contact between the particles. In contrast, $50 \mu \mathrm{m}$ particle size gave a thinner suspension, which was less viscous compared to that of the $36 \mu \mathrm{m}$ zeolite particle. The least viscous suspension using $75 \mu \mathrm{m}$ zeolite powder was obtained.

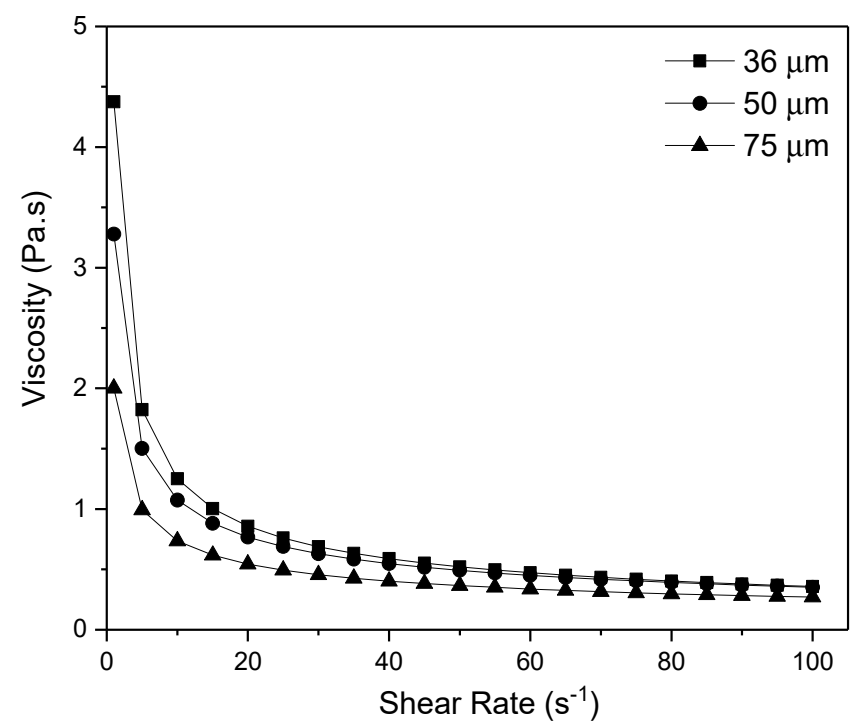

Figure 2. Rheological profile of suspension containing zeolite/NMP/PESf/Arlacel with different sizes of zeolite particle. 
According to Kingsbury and Li, the viscosity of dope suspension mainly dominates the formation of finger-like structure on the HFCM [35]. Their study showed that the formation of finger-like structure was more favorable, obtained from the use of the less viscous dope suspension. Kingsbury and Li also proposed the threshold value of the alumina dope suspension viscosity at $12.1 \mathrm{~Pa} \cdot \mathrm{s}$ at the shear rate of $30 \mathrm{~s}^{-1}$. The study also revealed that a viscosity exceeding this threshold value is less likely to produce a finger-like structure and, in turn, would be more dominated by the sponge-like structure formation across the membrane.

In this study, the viscosities of the suspension at the shear rate of $30 \mathrm{~s}^{-1}$ were $0.6880,0.6302$, and $0.4558 \mathrm{~Pa} \cdot \mathrm{s}$ for 36, 50, and $75 \mu \mathrm{m}$ zeolite, respectively. The decreasing trend of dope suspension viscosities as the particle size of zeolite increased resulted in the formation of more finger-like and/or macrovoid structures in the membrane. The less formation of finger-like structures attained in the membrane fabricated using $36 \mu \mathrm{m}$ zeolite particle indicates that this dope suspension was approaching the threshold value of the zeolite suspension. In other words, the formation of the sponge-like structure is more likely to be attained if the viscosity of the dope suspension is more than $0.6880 \mathrm{~Pa} \cdot \mathrm{s}$. Furthermore, the formation of sponge-like instead of finger-like structure in a thicker suspension is due to the demixing process between solvent and nonsolvent during the phase inversion process. A similar finding was obtained by Kingsbury et al. on the dope suspension thickening effect toward the control of finger- and sponge-like structures across the membranes [36].

\subsubsection{Morphological Behavior of the HFCM}

The morphology of the HFCM spun using different grades of natural zeolite particle sizes is depicted in Figure 3. The SEM micrographs of the HFCM were taken at different magnifications. The particle size plays an important role in determining the morphological structures of the membrane. As discussed in the previous section, the HFCM structure is mainly affected by the viscosity of the ceramic dope suspension. The HFCM spun by the most viscous dope suspension (36 $\mu$ m of zeolite powder) resulted in the densest membrane structure and the thickest membrane wall. The highly viscous dope suspension, despite the same ceramic loading and sintering temperature, produced a more packed membrane. The finer ceramic particles were closely packed in a uniform arrangement, and thus the formation of pore or voids in between the ceramic particles was reduced.

Apart from the cross-sectional morphology of the HFCM, the SEM analysis was also done to evaluate the inner and outer surfaces of the HFCMs (Figure 4). The outer surface of the HFCM lumen was rougher than the inner surface. The particle distribution and arrangement on the membrane surface were highly influenced by the bore fluid effect during the phase inversion process. During the process, the internal coagulant that acted as the lumen former for the HFCM has indirectly arranged the particle of the zeolite uniformly. The hydrodynamic force of the bore fluid eventually thrusted the dope suspension as well as the ceramic particle to a more packed arrangement, resulting in a smooth surface [37]. On the other hand, the rough surface of the outer contour of the HFCM might be due to the weak hydrodynamic force of the external coagulant, reducing the solidification rate of the dope suspension at the outer surface. Additionally, the inner surface of the HFCM showed cracking upon the increment in the particle size of the natural zeolite powder. This phenomenon could be attributed to the thinning effect of the dope suspension when the bigger ceramic particles were used. The high hydrodynamic force thrusted the ceramic particles within the thin dope suspension, thus promoting the crack formation. This defect also weakened the membrane strength. The arrangement of the ceramic particles on the outer surface was loose and less packed compared to that on the internal surface. This occurrence is important because it determines the effectiveness of the adsorption process, which mainly depends on the surface area of the adsorbent. A bigger surface area possesses a better adsorption performance. This bigger surface area normally comes from the rough surface. Figure 5 illustrates the phase inversion process that contributed to the formation of the smooth inner surface and the rough outer surface of the HFCM. 

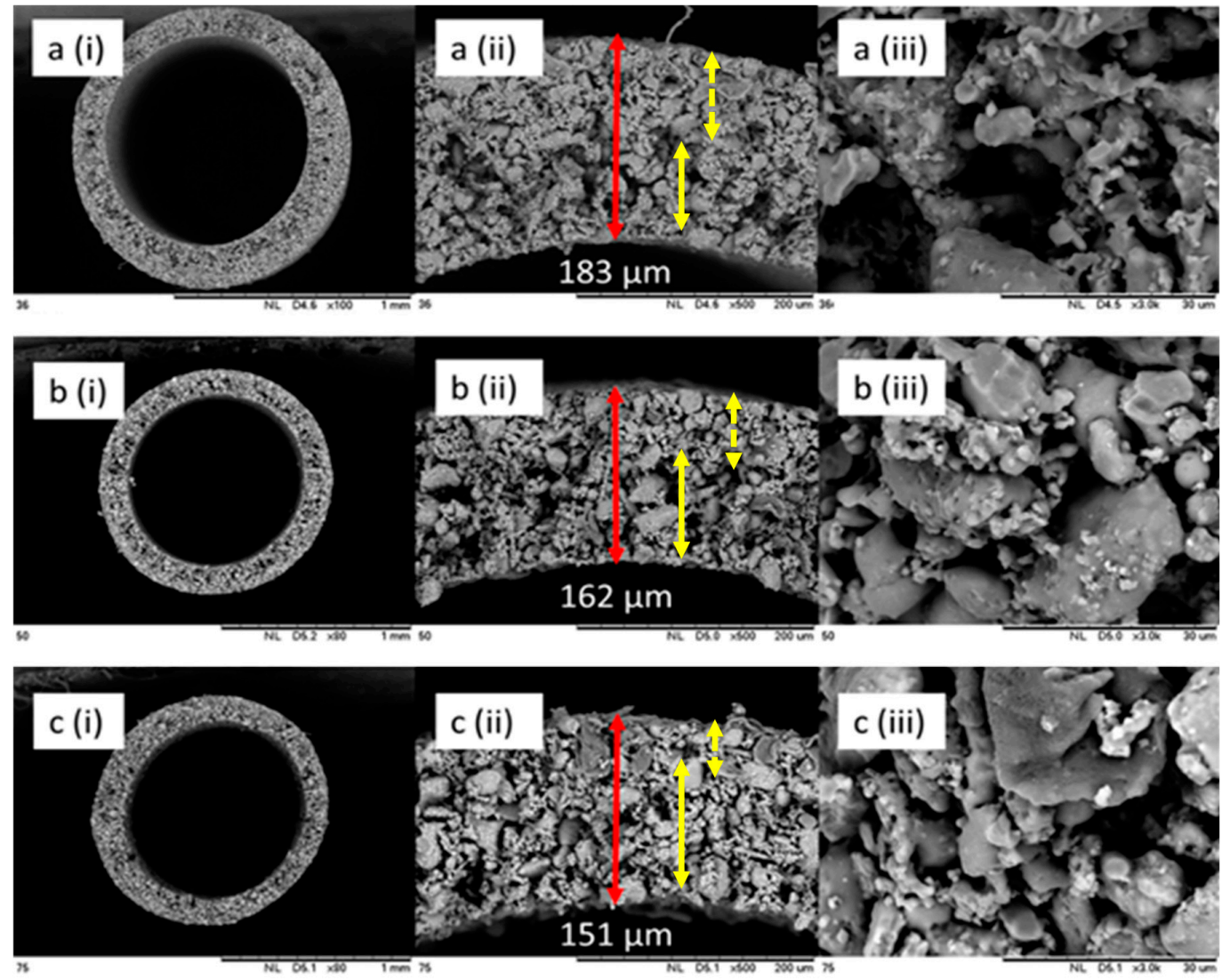

Figure 3. Scanning electron microscopy (SEM) micrographs of the HFCMs at different magnifications (i) $\times 60$, (ii) $\times 500$ and (iii) $\times 3000$ of (a) $36 \mu \mathrm{m}$, (b) $50 \mu \mathrm{m}$, and (c) $75 \mu \mathrm{m}$, spun at $45 \mathrm{wt} \%$ ceramic loading, $5 \mathrm{~cm}$ of air-gap distance and $15 \mathrm{~mL} / \mathrm{min}$ of bore fluid flowrate. (Note: full yellow arrow noted the finger-like or macro void region while dotted arrow showed the sponge-like structure).

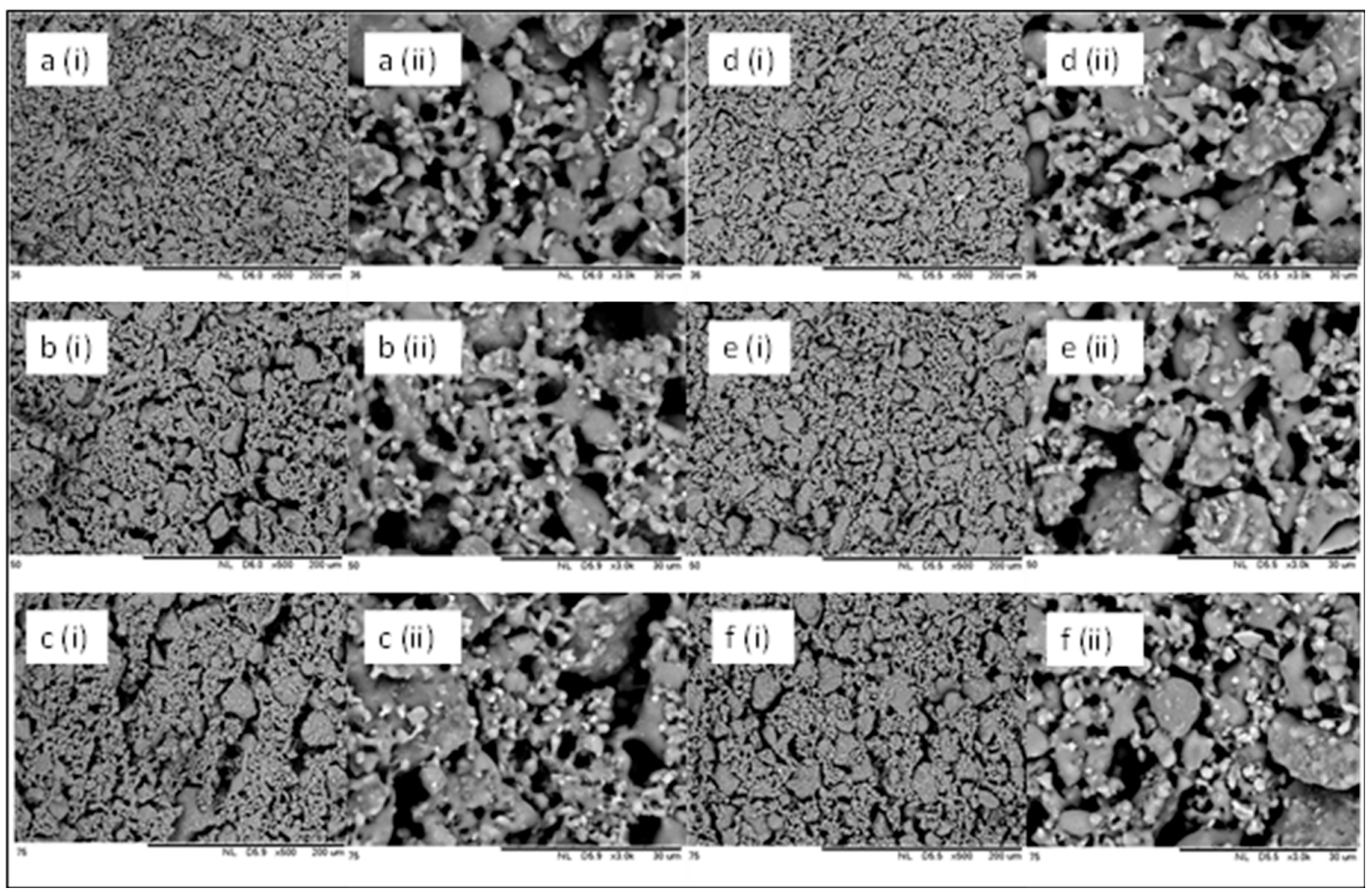

Figure 4. SEM micrographs of the HFCMs of inner surface of (a) $36 \mu \mathrm{m}$, (b) $50 \mu \mathrm{m}$, and (c) $75 \mu \mathrm{m}$, and outer surface of (d) $36 \mu \mathrm{m}$, (e) $50 \mu \mathrm{m}$, and (f) $75 \mu \mathrm{m}$ at different magnifications of (i) $\times 60$ and (ii) $\times 500$. 


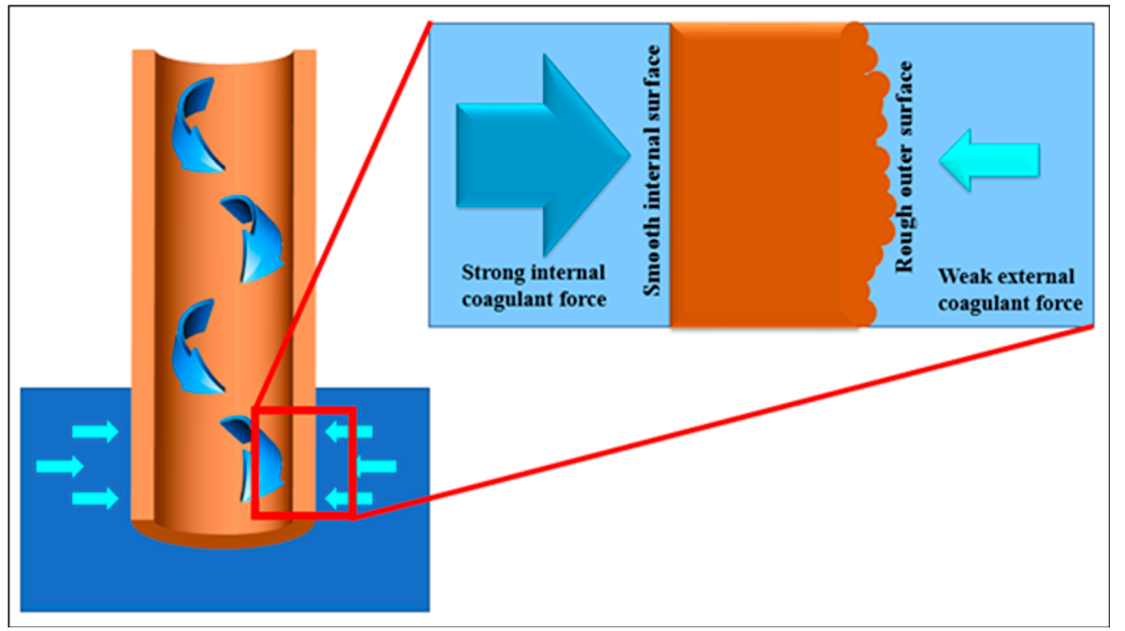

Figure 5. The illustration of the phase inversion process that influences the physical appearance of the inner and outer surfaces of the HFCM.

The microtopography of the natural zeolite powder and the HFCM derived from the natural zeolite (upon the sintering process) was analyzed using TEM and is depicted in Figure 6. The HFCM spun using the $36 \mu \mathrm{m}$ zeolite powder was selected for this analysis. The raw natural zeolite had a lamellar structure. The natural zeolite edges were sharp with more tubular particles. Upon the sintering process, the natural zeolite edges melted, resulting in a smoother, thinner, and more rounded shape compared to the unsintered natural zeolite powder. This change may affect the membrane performance as the surface area of the HFCM was reduced because of the heat treatment. A similar observation was reported on the modification of the natural zeolite using acid soaking where the edge of the zeolite particles softened [38]. The smoother surface offers a limited surface area/volume compared to the rougher surface and is expected to give better adsorption toward the ammonia removal. However, the adsorption/filtration process does not only rely on the surface area for better adsorption efficiency.

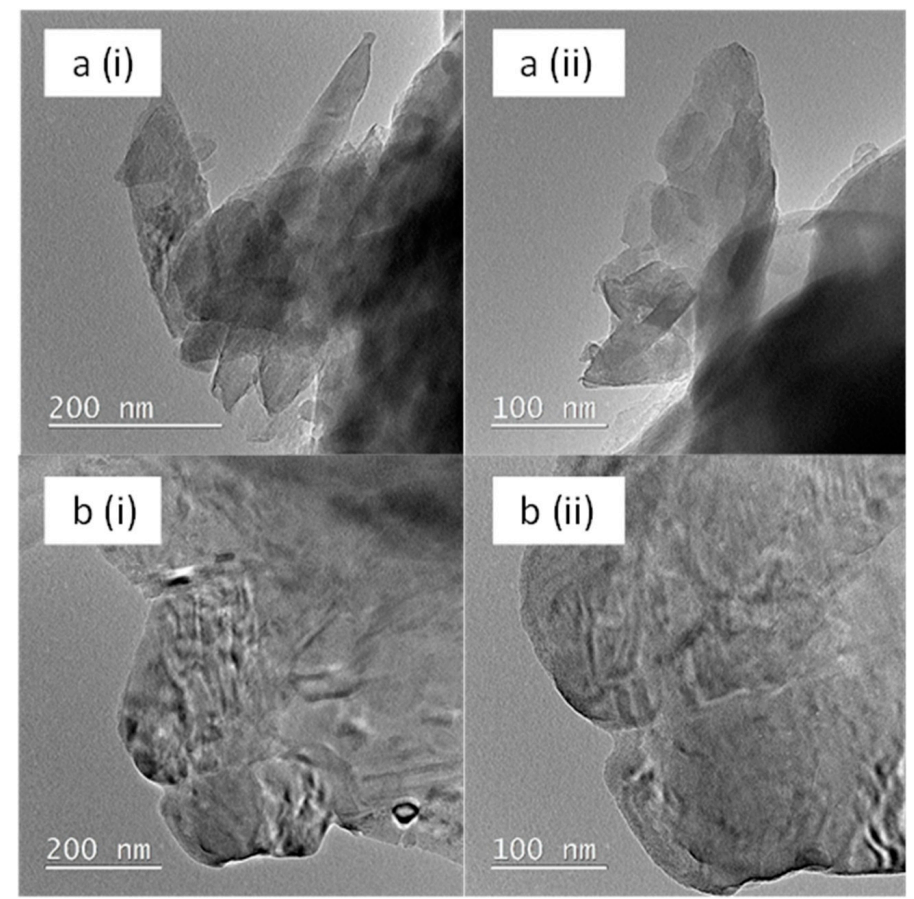

Figure 6. The transmittance electron microscopy (TEM) microtopography of the (a) natural zeolite powder and (b) HFCM derived from the $36 \mu \mathrm{m}$ natural zeolite, at different magnifications of (i) $\times 60$ and (ii) $\times 500$. 


\subsubsection{Crystallinity Properties of the HFCM}

The XRD patterns of the natural zeolite and HFCM are depicted in Figure 7. The XRD analysis of the natural zeolite was validated by the diffraction peaks at $2 \theta$ of $9.768^{\circ}, 11.105^{\circ}, 13.220^{\circ}, 16.796^{\circ}$, $18.894^{\circ}, 20.762^{\circ}, 22.247^{\circ}, 22.615^{\circ}, 25.930^{\circ}, 26.547^{\circ}, 28.040^{\circ}, 29.885^{\circ}, 31.861^{\circ}, 32.580^{\circ}, 36.451^{\circ}$, and $50.051^{\circ}$ and was confirmed by the standard pattern of the clinoptilolite (01-079-1460 JCPDS card). This pattern of peaks indicates that the main phase of this natural zeolite is clinoptilolite. The same trend of finding was reported in the literature [39]. Additionally, a slight amount of quartz and cristobalite phases were found in the XRD pattern of this natural zeolite sample. It is believed that these phases exist due to the presence of impurities. Upon the sintering process, the crystallinity of the natural zeolite was changed because of the heat treatment. The comparative analysis between these two peaks revealed less intense peaks for the heat-treated sample of the HFCM. In addition, some amorphous structures formed in the HFCM sample upon the sintering process. This was confirmed by the disappearance of some peaks on the diffractogram. The disappearance of major peaks of clinoptilolite was observed in all spectra of the HFCM. Additionally, the spectra of all HFCMs showed that the major phases present were quartz (01-083-2187 JCPDS card), cristobalite (01-077-8629 JCPDS card), and anorthoclase (01-077-8526 JCPDS card). The flattening of peaks of natural zeolite upon the sintering process was due to the burn-off process of the elements. Hence, the remaining peaks belong to the crystal phase with a high melting point. Similar findings were reported when different treatments were done on the natural zeolite sample $[40,41]$. As mentioned earlier in the previous section, the heat treatment reduced the surface area of the natural zeolite because of the grain growth phenomenon that merged the natural zeolite particles toward the end of the process [42]. On the other hand, the particle size plays no significant role in the changes in the crystal phase of the HFCM. This is proven by the presence of all phase peaks in all diffractograms.

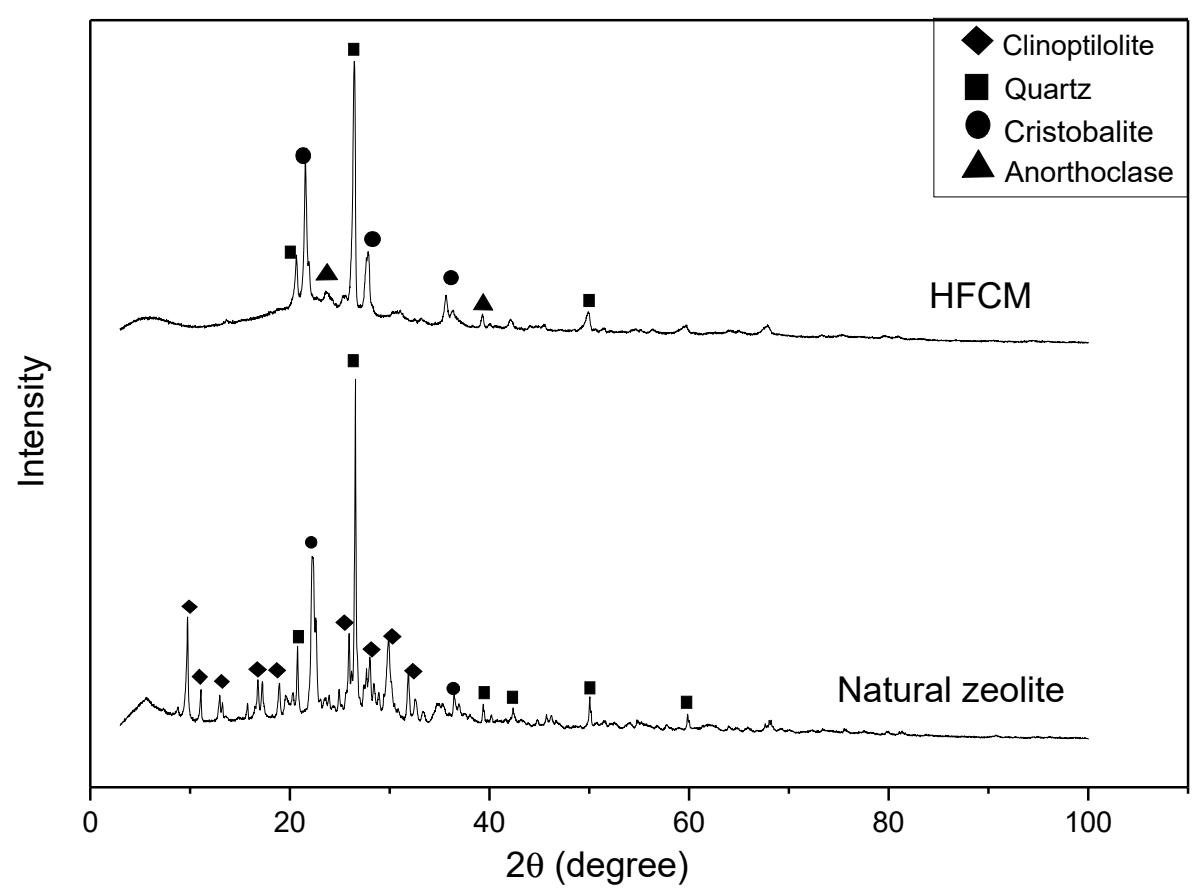

Figure 7. The X-ray diffraction analysis (XRD) patterns of the natural zeolite and HFCM.

\subsubsection{Mechanical Strength and Water Permeability of the HFCM}

Apart from the physicochemical properties of the morphological and crystallinity behaviors of the produced HFCM, the mechanical strength of the HFCM was significantly influenced by the particle size of the natural zeolite used in the fabrication step. Figure 8a depicts the mechanical 
strength of each HFCM produced by different grades of the zeolite particle size. The mechanical strength of the HFCM significantly decreased with the increment in the particle size of the natural zeolites. The mechanical strength of the HFCM with $36 \mu \mathrm{m}$ zeolite of $52.92 \mathrm{MPa}$ decreased to more than half upon the increment in zeolite powder size to $75 \mu \mathrm{m}$. The value of the mechanical strength of the HFCM in this work is comparable to those reported in other studies, although the sintering temperature in this study is much lower [37,43]. The reduction in the HFCM mechanical strength could possibly be due to the particle arrangement in the structure. The smaller particles were aligned in a more uniform structure with a closely packed and dense assemble. This phenomenon is clearly seen from the cross-sectional micrograph of each membrane (Figure 3). Besides the compact structure, the membrane produced possessed less gap or space between the particles. The bigger space or gap between the particles may lead to defect formation in the structure, reducing the mechanical strength of the HFCM. Likewise, this concept of structural densification shows some similarity to the effect of sintering temperature [37]. In the sintering process, the ceramic membrane structure is affected by the grain growth phenomenon. The higher the temperature, the better the mechanical strength due to the densified structure with closely packed ceramic particles. This phenomenon could be imitated by the particle size effect. The smaller particles tend to form a denser membrane, increasing its strength.

(a)

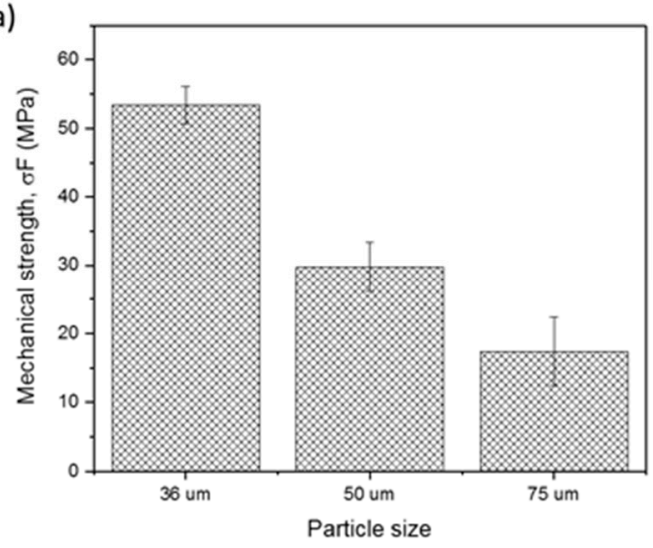

(b)

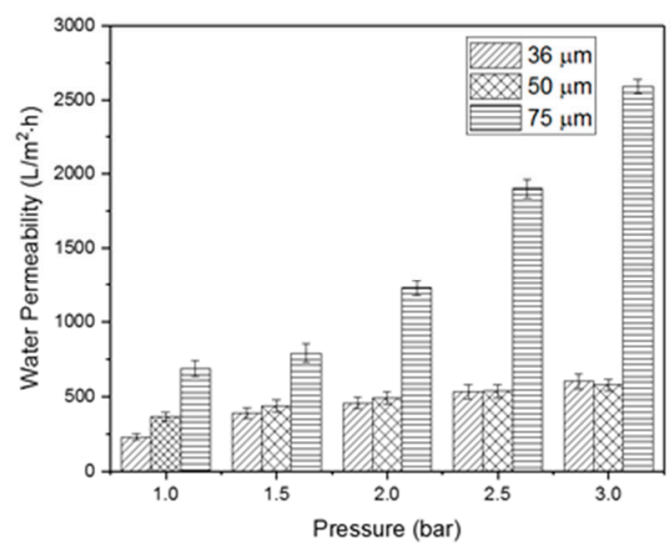

Figure 8. (a) The mechanical strength of the HFCM derived from different grade of natural zeolite particle sizes $(n=5)$ and $(\mathbf{b})$ pure water permeability profile of the HFCM derived from different grade of natural zeolite particle sizes at different water pressure $(n=3)$.

Another physical property that determines the effectiveness of the ceramic membrane is water permeability. Figure $8 \mathrm{~b}$ shows the water permeation profiles of the HFCMs fabricated using different grades of natural zeolite particle size at different pressures. The water permeability increased with the increment in natural zeolite particle size. The lowest water permeability was recorded in the $36 \mu \mathrm{m}$ zeolite HFCM of $228.25 \mathrm{~L} / \mathrm{m}^{2} \cdot \mathrm{h}$ at 1 bar. At the same pressure, the water permeability significantly increased to $687.93 \mathrm{~L} / \mathrm{m}^{2} \mathrm{~h}$ when the membrane was changed to the $75-\mu \mathrm{m}$ zeolite HFCM. Upon the increment in the water pressure, each HFCM possessed a significantly increased water permeation with the $75-\mu \mathrm{m}$ zeolite HFCM recording the highest permeability of $2589.84 \mathrm{~L} / \mathrm{m}^{2} \mathrm{~h}$ at 3 bar. In comparison, the lowest was $601.06 \mathrm{~L} / \mathrm{m}^{2} \mathrm{~h}$, achieved by the $36-\mu \mathrm{m}$ zeolite HFCM under the same condition. These findings show that the water permeability of the HFCM is mainly determined by the morphology of the membrane.

Similar to the mechanical strength, the compactness of the ceramic particles in the membrane structure mainly affected the permeability of the HFCM. The more compact the membrane structure (mainly achieved by the smaller natural zeolite particles), the lower the water permeability. The effect of particle size had been studied and reported [28]. The effect of ceramic particle size was almost similar to that observed in this study. 
The permeability and compactness of the HFCM are further supported by the porosity data obtained via the mercury intrusion porosimetry analysis. Figure 9 a depicts the pore size distribution of the HFCMs derived from different ceramic particle sizes. Different particle sizes did not merely affect the pore size distribution of the membrane. The same range of the membrane pore size between 2.8 and $10.3 \mu \mathrm{m}$ were not changed for all the membranes from different particle sizes. A similar trend of finding was reported in another study [44]. The single broad peak possessed by each membrane indicates that the membranes were composed of symmetrical sponge-like structure, represented by uniform pore formation throughout the membrane. Additionally, the mercury intrusion intensity decreased upon the reduction of the ceramic particle size. This indicates that the pore size became smaller, which is attributable to the smaller particle size. Othman et al. reported the same findings in their study [45]. In addition, the slight mercury intrusion in the smaller range of pore size $(0.18-1.5 \mu \mathrm{m})$ indicates the grain boundaries of the natural zeolite particles contained in the membrane [46].

In addition, the mercury intrusion porosimetry analysis also signifies the porosity degree of the produced membrane. Figure $9 \mathrm{~b}$ shows that the increment in particle size increased the porosity of the membranes produced with porosity degrees of more than $45 \%$, which indicates that the produced membranes were composed of relatively large pores that were sufficiently porous for a ceramic membrane [47]. The higher degree of membrane porosity is crucial for the determination of higher water permeability, where it is highly required for the water treatment process membranes [48]. These findings reveal that the membrane fabricated using larger particle size possessed a higher water permeability, resulting in the poorest ammonia uptake through the adsorption process.
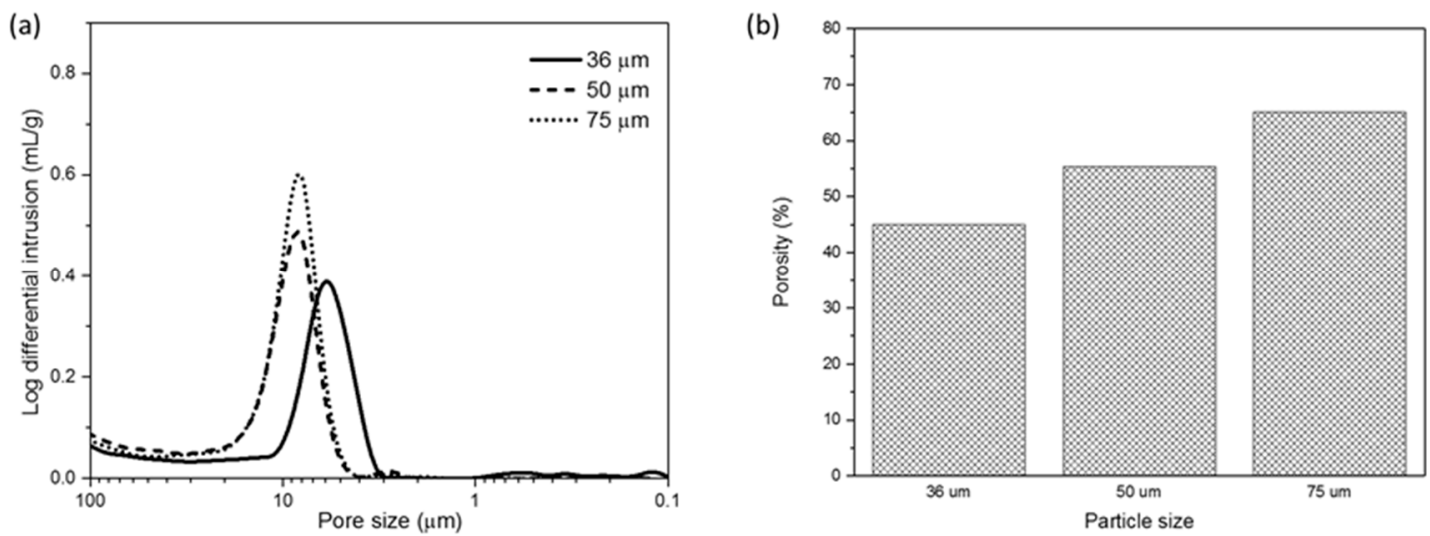

Figure 9. (a) The pore size distribution of the HFCM fabricated from different natural zeolite particle size and (b) porosity of the HFCM fabricated from different natural zeolite particle size.

\subsection{Ammonia Removal by Natural Zeolite HFCM}

The adsorptive performance of the HFCM toward ammonia removal was evaluated using the adsorptive HFCM derived from different grades of natural zeolite particle size. Figure 10 depicts the percentage of removal and water permeability of the $50 \mathrm{mg} / \mathrm{L}$ ammonia feed solution at 1 bar and $\mathrm{pH}$ 7. The pressure was chosen because of the lowest permeability produced, increasing the residence time acquired for a better adsorption process [49]. The membrane with the smallest particle size $(36 \mu \mathrm{m})$ showed the highest ammonia removal of $96.67 \%$. The high performance of ammonia rejection could be attributed to the low water permeability of the feed solution $\left(201.54 \mathrm{~L} / \mathrm{m}^{2} \mathrm{~h}\right)$. A low water permeation leads to high adsorption because of the long residence time between the adsorbate and adsorbent. According to Foo et al. the adsorption rate increases rapidly at the early stage, ascribed to the readily accessible active sites on the adsorbent [49]. Upon prolonged contact, the adsorbate uptake becomes less efficient because access to active sites is limited. Also, the reduced adsorption performance could possibly be due to insufficient residence time for the adsorbate within the adsorptive membrane at high permeation, because the ammonia solution left the membrane before equilibrium was attained [50]. Thus, the 75- $\mu \mathrm{m}$ zeolite HFCM, which possessed the highest water permeability, yielded the lowest ammonia uptake. 


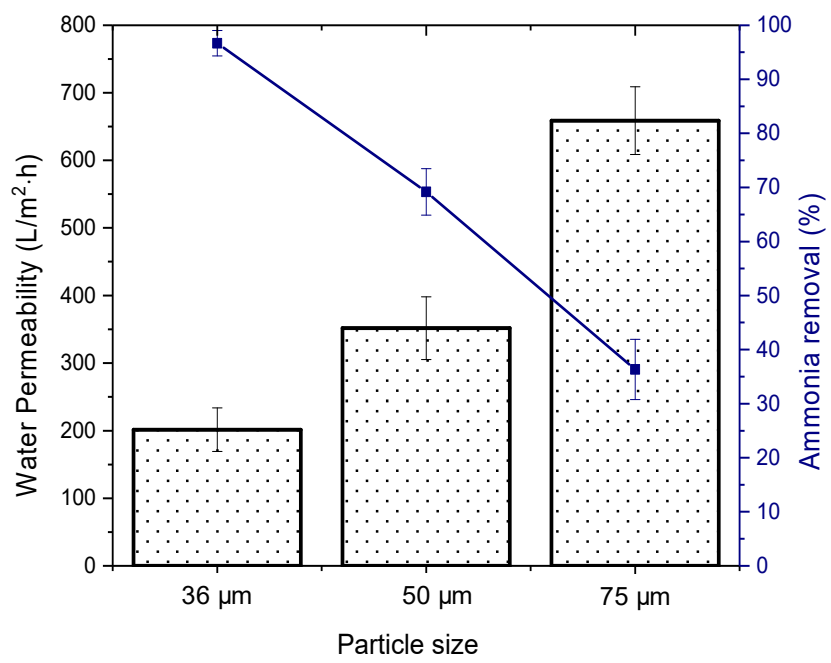

Figure 10. The ammonia removal and water permeability of the adsorptive HFCM derived from different particle size $(n=3)$.

Figure 11 illustrates the interaction of the membrane particle compactness (contributed by the particle size) and its water permeability and adsorption performances. The more compact membranes, attained by the smallest particle, retain (delays) more water to pass through the membrane that eventually prolongs the retention time for an effective adsorption process. Apart from the interparticle interaction, the adsorption of ammonia can also be attributed to the intraparticle pore structure. Figure 12 depicts the schematic of the intraparticle pores of an adsorbent for the adsorption process [51]. The presence of pores in an adsorbent particle increases the adsorption surface that serves as the active site for the adsorption to occur [52]. Besides promoting a more compact membrane structure, smaller natural zeolite particles also offer more surface area (including the intraparticle pores, namely macropore, mesopore, and micropore) that finally increases the adsorption capacity of the fabricated membranes.

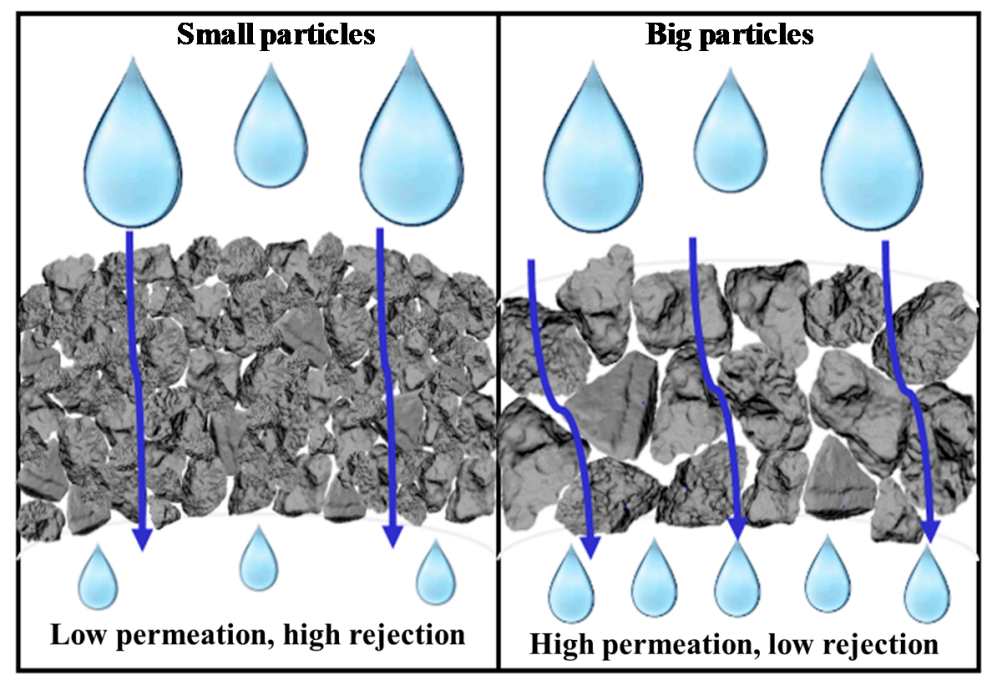

Figure 11. The illustration of the relationship between particle size, membrane compactness, water permeability, and ammonia rejection (adsorption).

In addition, the efficiency of the natural zeolite clinoptilolite in adsorbing ammonia showed a good performance where up to $96.67 \%$ of ammonia was successfully removed from the feed solution. This excellent behavior indicates that natural zeolite clinoptilolite possesses a great potential to be developed as an adsorptive membrane. Table 1 lists the ammonia removal efficiencies of several 
natural zeolites, particularly clinoptilolite, in the form of powder suspension compared to this study (adsorptive membrane). The findings show that the ammonia removal in this study is compatible with that of natural zeolites reported in the literature. Therefore, the ammonia adsorption intention for this study is highly achievable and practical.

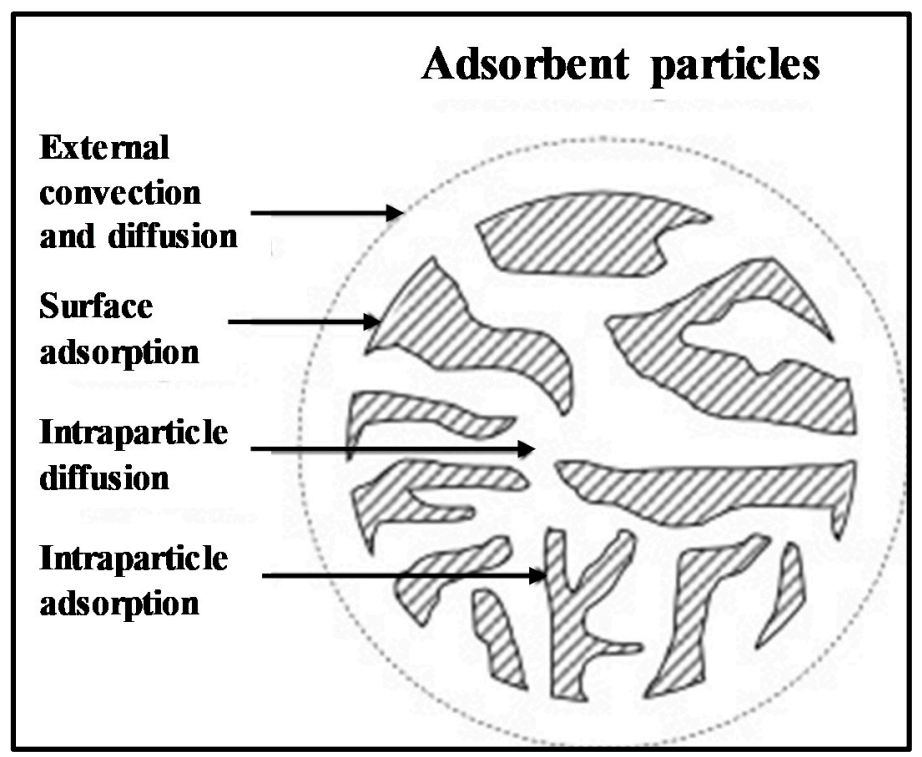

Figure 12. The schematic intraparticle pores of an adsorbent particle in adsorption process [51].

Table 1. Ammonia adsorption by natural zeolite clinoptilolites.

\begin{tabular}{clccc}
\hline Material & Material Form & $\begin{array}{c}\text { Initial Ammonia } \\
\text { Concentration } \\
(\mathbf{m g} / \mathbf{L})\end{array}$ & $\begin{array}{c}\text { Ammonia } \\
\text { Removal } \\
\mathbf{( \% )}\end{array}$ & Reference \\
\hline Canadian clinoptilolite & Powder suspension & 100 & 65 & {$[53]$} \\
\hline Chinese clinoptilolite & Powder suspension & 115 & 70 & {$[54]$} \\
\hline Chinese Na-clinoptilolite & Powder suspension & 250 & 77.16 & {$[55]$} \\
\hline Croatian clinoptilolite & Powder suspension & 100 & 61.1 & {$[56]$} \\
\hline Croatian clinoptilolite & Powder suspension & 800 & 75 & {$[57]$} \\
\hline Iranian clinoptilolite & Powder suspension & 100 & 68 & {$[58]$} \\
\hline New Zealand clinoptilolite & Powder suspension & 40 & 85.09 & {$[59]$} \\
\hline Turkish clinoptilolite & Powder suspension & 150 & 70 & {$[60]$} \\
\hline USA clinoptilolite & Powder suspension & 250 & 56 & {$[61]$} \\
\hline Natural zeolite clinoptilolite & Adsorptive membrane & 50 & 82.97 & This study \\
\hline
\end{tabular}

On the other hand, this study serves as a new perspective on the fabrication of low-cost ceramic membranes for various applications. Table 2 summarizes the fabrication of low-cost membranes derived from various materials and targeted for different applications. Low-cost membranes have been widely used for many applications. Of all the applications, these membranes are mainly used for water treatment processes, including oil-water separation, dye removal, suspended solid filtration, and heavy metal elimination. Therefore, all these studies have revealed that low-cost membrane fabricated from natural raw materials and waste products are capable of achieving high performance in treating the wastewater from various industries. 
Table 2. Low-cost membranes and its applications.

\begin{tabular}{|c|c|c|c|c|c|}
\hline Material & $\begin{array}{c}\text { Fabrication } \\
\text { Method }\end{array}$ & $\begin{array}{c}\text { Sintering } \\
\text { Temperature } \\
\left({ }^{\circ} \mathrm{C}\right)\end{array}$ & Application & $\begin{array}{l}\text { Membrane } \\
\text { Mechanism }\end{array}$ & Reference \\
\hline Kaolin & Extrusion & $1200-1500$ & $\begin{array}{l}\text { Arsenic } \\
\text { removal }\end{array}$ & $\begin{array}{l}\text { Membrane } \\
\text { distillation }\end{array}$ & [62] \\
\hline Chinese clay & Paste casting & 400 & $\begin{array}{l}\text { Oil-in-water } \\
\text { separation }\end{array}$ & Filtration & [63] \\
\hline Iranian clay & Pressing & 900 & $\begin{array}{l}\text { Cationic dye } \\
\text { removal }\end{array}$ & $\begin{array}{l}\text { Adsorption } \\
\text { Filtration + }\end{array}$ & {$[64]$} \\
\hline $\begin{array}{l}\text { Kaolin }+ \\
\text { Limestone }\end{array}$ & Extrusion & $800-1100$ & Support layer & Filtration & [65] \\
\hline Indian clay & Paste casting & 800-1000 & $\begin{array}{c}\text { Chromate } \\
\text { removal }\end{array}$ & $\begin{array}{l}\text { Flocculation }+ \\
\text { Filtration }\end{array}$ & [66] \\
\hline Fly ash & Extrusion & 1100-1500 & Support layer & Filtration & [20] \\
\hline $\begin{array}{l}\text { Fly ash + } \\
\text { bauxite }\end{array}$ & Pressing & $1200-1500$ & $\begin{array}{l}\text { Oil-in-water } \\
\text { separation }\end{array}$ & Filtration & [67] \\
\hline $\begin{array}{l}\text { Kaolin + } \\
\text { Calcium } \\
\text { carbonate }\end{array}$ & Extrusion & 1150-1300 & Support layer & Filtration & [68] \\
\hline Brazilian clay & Pressing & 1050 & $\begin{array}{c}\text { Microalgae } \\
\text { removal }\end{array}$ & Filtration & [69] \\
\hline $\begin{array}{l}\text { Natural zeolite } \\
\text { clinoptilolite }\end{array}$ & $\begin{array}{c}\text { Phase inversion } \\
\text { extrusion }\end{array}$ & 1050 & $\begin{array}{l}\text { Ammonia } \\
\text { removal }\end{array}$ & $\begin{array}{l}\text { Adsorption + } \\
\text { Filtration }\end{array}$ & This study \\
\hline
\end{tabular}

\section{Conclusions}

This paper presents the characteristics study as well as the feasibility of HFCM derived from the natural zeolite for the adsorption of ammonia from wastewater. Different grades of zeolite particle size were used to fabricate the HFCM and extruded at fixed membrane fabrication parameters. The physicochemical properties of the HFCM were thoroughly examined and observed throughout this study. It is concluded that the particle size plays an important role in determining the properties of the membrane and thus controls its performance. The zeolite with $36 \mu \mathrm{m}$ particle size possesses the most promising role in producing the best HFCM accompanied with the most favorable physical properties, namely morphology, mechanical strength, and water permeability. These properties are vital in the adsorptive performance of the ammonia removal. The compact and uniform particles in the membrane structure assured the acceptable strength for the experimental handling. In addition, this feature has an added value in slowing down the water permeability of the membrane, ensuring high performance for the adsorption process with more than $96 \%$ of ammonia removal. Additionally, the best possible sintering temperature aided the formation of the compact HFCM through the grain growth process along with the membrane densification process. This research will certainly provide a better understanding of the fabrication of effective adsorptive HFCM with controlled morphology, mechanical strength, and water permeability to improve the adsorption capability for ammonia removal.

Author Contributions: Conceptualization, M.R.A. and M.H.D.O.; methodology, M.R.A. and M.H.D.O.; validation, M.R.A., M.H.D.O., S.H.S.A.K., M.N.M.S., Y.I., M.T., S.H., M.H.P., M.A.R. and J.J.; formal analysis, M.R.A., M.H.D.O., Y.I., M.T., S.H.; investigation, M.R.A., M.H.D.O., Y.I., M.T., S.H.; resources, M.H.D.O., S.H.S.A.K., M.N.M.S., Y.I., M.T., S.H., M.H.P.; data curation, M.R.A.; writing—original draft preparation, M.R.A.; writing—review and editing, M.H.D.O., S.H.S.A.K., M.N.M.S., Z.S.T., Y.I., M.T., S.H., M.H.P., M.A.R. and J.J; visualization, M.R.A.; supervision, M.H.D.O., S.H.S.A.K., and M.H.P.; project administration, M.H.D.O. and S.H.S.A.K.; funding acquisition, M.H.D.O. and S.H.S.A.K. All authors have read and agreed to the published version of the manuscript.

Funding: The authors gratefully acknowledge financial support from the Ministry of Education Malaysia under the Higher Institution Centre of Excellence Scheme (Project Number: R.J090301.7809.4J430) and Fundamental 
Research Grant Scheme (FRGS) (Project Number: R.J130000.7809.5F161), and Universiti Teknologi Malaysia under the Transdisciplinary Research Grant (Project number: Q.J130000.3509.05G75), Malaysia Research University Network (MRUN) Grant (Project number: R.J130000.7809.4L867), and UTM High Impact Research (HIR) Grant (Project number: Q.J130000.2409.08G34). The authors also would like to acknowledge Universiti Teknologi MARA under the BESTARI Grant Scheme (Project Number: 600-IRMI/DANA5/3/BESTARI (P) (005/2018)) and Malaysia Research University Network (MRUN) Grant (Project number: 100-IRMI/GOV 16/6/2 (002/2019)).

Acknowledgments: The authors would also like to thank Research Management Centre, Universiti Teknologi Malaysia and Research Management Institute, Universiti Teknologi MARA for their technical support.

Conflicts of Interest: The authors declare no conflict of interest.

\section{References}

1. Renge, V.; Khedkar, S.; Pande, S.V. Removal of heavy metals from wastewater using low cost adsorbents: A review. Sci. Rev. Chem. Commun. 2012, 2, 580-584.

2. Shannon, M.A.; Bohn, P.W.; Elimelech, M.; Georgiadis, J.G.; Marinas, B.J.; Mayes, A.M. Science and technology for water purification in the coming decades. In Nanoscience and Technology: A Collection of Reviews from Nature Journals; World Scientific: Singapore, 2010; pp. 337-346.

3. Atkins, P.F., Jr.; Scherger, D.A. A review of physical-chemical methods for nitrogen removal from wastewater. In Proceedings of the Conference on Nitrogen as a Water Pollutant; Elsevier: Pergamon, Turkey, 2013; pp. 713-719. [CrossRef]

4. Shi, P.; Wang, Q.; Xu, Y.; Luo, W. Corrosion behavior of bulk nanocrystalline copper in ammonia solution. Mater. Lett. 2011, 65, 857-859. [CrossRef]

5. Qiu, W.; Kosuri, M.; Zhou, F.; Koros, W.J. Dehydration of ethanol-water mixtures using asymmetric hollow fiber membranes from commercial polyimides. J. Membr. Sci. 2009, 327, 96-103. [CrossRef]

6. Abdel-Karim, A.; Gad-Allah, T.A.; El-Kalliny, A.S.; Ahmed, S.I.; Souaya, E.R.; Badawy, M.I.; Ulbricht, M. Fabrication of modified polyethersulfone membranes for wastewater treatment by submerged membrane bioreactor. Sep. Purif. Technol. 2017, 175, 36-46. [CrossRef]

7. An, A.K.; Guo, J.; Jeong, S.; Lee, E.-J.; Tabatabai, S.A.A.; Leiknes, T. High flux and antifouling properties of negatively charged membrane for dyeing wastewater treatment by membrane distillation. Water Res. 2016, 103, 362-371. [CrossRef]

8. Setiawan, L.; Wang, R.; Li, K.; Fane, A.G. Fabrication of novel poly (amide-imide) forward osmosis hollow fiber membranes with a positively charged nanofiltration-like selective layer. J. Membr. Sci. 2011, 369, 196-205. [CrossRef]

9. Srijaroonrat, P.; Julien, E.; Aurelle, Y. Unstable secondary oil/water emulsion treatment using ultrafiltration: Fouling control by backflushing. J. Membr. Sci. 1999, 159, 11-20. [CrossRef]

10. Cui, J.; Zhang, X.; Liu, H.; Liu, S.; Yeung, K.L. Preparation and application of zeolite/ceramic microfiltration membranes for treatment of oil contaminated water. J. Membr. Sci. 2008, 325, 420-426. [CrossRef]

11. Guizard, C.; Ayral, A.; Julbe, A. Potentiality of organic solvents filtration with ceramic membranes. A comparison with polymer membranes. Desalination 2002, 147, 275-280. [CrossRef]

12. DeFriend, K.A.; Wiesner, M.R.; Barron, A.R. Alumina and aluminate ultrafiltration membranes derived from alumina nanoparticles. J. Membr. Sci. 2003, 224, 11-28. [CrossRef]

13. Masmoudi, S.; Amar, R.B.; Larbot, A.; El Feki, H.; Salah, A.B.; Cot, L. Elaboration of inorganic microfiltration membranes with hydroxyapatite applied to the treatment of wastewater from sea product industry. J. Membr. Sci. 2005, 247, 1-9. [CrossRef]

14. Hedfi, I.; Hamdi, N.; Rodriguez, M.A.; Srasra, E. Preparation of macroporous membrane using natural Kaolin and Tunisian lignite as a pore-forming agent. Desalin. Water Treat. 2016, 57, 13388-13393. [CrossRef]

15. Fang, J.; Qin, G.; Wei, W.; Zhao, X. Preparation and characterization of tubular supported ceramic microfiltration membranes from fly ash. Sep. Purif. Technol. 2011, 80, 585-591. [CrossRef]

16. Bai, C.-Y.; Li, Y.; Liu, Z.-M.; Liu, P.-W.; Deng, X.-Y.; Li, J.-B.; Yang, J. Fabrication and properties of mullite-bonded porous $\mathrm{SiC}$ membrane supports using bauxite as aluminum source. Ceram. Int. 2015, 41, 4391-4400. [CrossRef]

17. Tran, H.N.; You, S.-J.; Hosseini-Bandegharaei, A.; Chao, H.-P. Mistakes and inconsistencies regarding adsorption of contaminants from aqueous solutions: A critical review. Water Res. 2017, 120, 88-116. [CrossRef] 
18. Hubadillah, S.K.; Othman, M.H.D.; Matsuura, T.; Ismail, A.F.; Rahman, M.A.; Harun, Z.; Jaafar, J.; Nomura, M. Fabrications and applications of low cost ceramic membrane from kaolin: A comprehensive review. Ceram. Int. 2018, 44, 4538-4560. [CrossRef]

19. Abdullayev, A.; Bekheet, M.F.; Hanaor, D.A.; Gurlo, A. Materials and Applications for Low-Cost Ceramic Membranes. Membranes 2019, 9, 105. [CrossRef]

20. Zhu, L.; Chen, M.; Dong, Y.; Tang, C.Y.; Huang, A.; Li, L. A low-cost mullite-titania composite ceramic hollow fiber microfiltration membrane for highly efficient separation of oil-in-water emulsion. Water Res. 2016, 90, 277-285. [CrossRef]

21. Kouvelos, E.; Kesore, K.; Steriotis, T.; Grigoropoulou, H.; Bouloubasi, D.; Theophilou, N.; Tzintzos, S.; Kanelopoulos, N. High pressure N2/CH4 adsorption measurements in clinoptilolites. Microporous Mesoporous Mater. 2007, 99, 106-111. [CrossRef]

22. Dong, Y.; Chen, S.; Zhang, X.; Yang, J.; Liu, X.; Meng, G. Fabrication and characterization of low cost tubular mineral-based ceramic membranes for micro-filtration from natural zeolite. J. Membr. Sci. 2006, 281, 592-599. [CrossRef]

23. Fane, A.G.; Wang, R.; Jia, Y. Membrane Technology: Past, Present and Future. In Membrane and Desalination Technologies; Wang, L.K., Chen, J.P., Hung, Y.-T., Shammas, N.K., Eds.; Humana Press: Totowa, NJ, USA, 2011; pp. 1-45. [CrossRef]

24. Yeon, S.-H.; Lee, K.-S.; Sea, B.; Park, Y.-I.; Lee, K.-H. Application of pilot-scale membrane contactor hybrid system for removal of carbon dioxide from flue gas. J. Membr. Sci. 2005, 257, 156-160. [CrossRef]

25. Nymeijer, D.; Visser, T.; Assen, R.; Wessling, M. Composite hollow fiber gas-liquid membrane contactors for olefin/paraffin separation. Sep. Purif. Technol. 2004, 37, 209-220. [CrossRef]

26. Wang, S.; Peng, Y. Natural zeolites as effective adsorbents in water and wastewater treatment. Chem. Eng. J. 2010, 156, 11-24. [CrossRef]

27. Adam, M.R.; Salleh, N.M.; Othman, M.H.D.; Matsuura, T.; Ali, M.H.; Puteh, M.H.; Ismail, A.F.; Rahman, M.A.; Jaafar, J. The adsorptive removal of chromium (VI) in aqueous solution by novel natural zeolite based hollow fibre ceramic membrane. J. Environ. Manag. 2018, 224, 252-262. [CrossRef]

28. Hubadillah, S.K.; Harun, Z.; Othman, M.H.D.; Ismail, A.F.; Gani, P. Effect of kaolin particle size and loading on the characteristics of kaolin ceramic support prepared via phase inversion technique. J. Asian Ceram. Soc. 2016, 4, 164-177. [CrossRef]

29. Kumar, P.S.; Korving, L.; Keesman, K.J.; van Loosdrecht, M.C.; Witkamp, G.-J. Effect of pore size distribution and particle size of porous metal oxides on phosphate adsorption capacity and kinetics. Chem. Eng. J. 2019, 358, 160-169. [CrossRef]

30. Adam, M.R.; Othman, M.H.D.; Hubadillah, S.K.; Puteh, M.H.; Harun, Z.; Ismail, A.F. Evaluating the sintering temperature control towards the adsorptivity of ammonia onto the natural zeolite based hollow fibre ceramic membrane. Int. J. Eng. Trans. B Appl. 2018, 31, 1398-1405. [CrossRef]

31. Zhao, T.; Li, S.-H.; Shen, L.; Wang, Y.; Yang, X.-Y. The sized controlled synthesis of MIL-101(Cr) with enhanced CO2 adsorption property. Inorg. Chem. Commun. 2018, 96, 47-51. [CrossRef]

32. Aghaei, Z.; Naji, L.; Hadadi Asl, V.; Khanbabaei, G.; Dezhagah, F. The influence of fumed silica content and particle size in poly (amide 6-b-ethylene oxide) mixed matrix membranes for gas separation. Sep. Purif. Technol. 2018, 199, 47-56. [CrossRef]

33. Sánchez-Laínez, J.; Zornoza, B.; Friebe, S.; Caro, J.; Cao, S.; Sabetghadam, A.; Seoane, B.; Gascon, J.; Kapteijn, F.; Le Guillouzer, C.; et al. Influence of ZIF-8 particle size in the performance of polybenzimidazole mixed matrix membranes for pre-combustion CO2 capture and its validation through interlaboratory test. J. Membr. Sci. 2016, 515, 45-53. [CrossRef]

34. María Arsuaga, J.; Sotto, A.; del Rosario, G.; Martínez, A.; Molina, S.; Teli, S.B.; de Abajo, J. Influence of the type, size, and distribution of metal oxide particles on the properties of nanocomposite ultrafiltration membranes. J. Membr. Sci. 2013, 428, 131-141. [CrossRef]

35. Kingsbury, B.F.K.; Li, K. A morphological study of ceramic hollow fibre membranes. J. Membr. Sci. 2009, 328, 134-140. [CrossRef]

36. Kingsbury, B.F.; Wu, Z.; Li, K. A morphological study of ceramic hollow fibre membranes: A perspective on multifunctional catalytic membrane reactors. Catal. Today 2010, 156, 306-315. [CrossRef] 
37. Li, L.; Chen, M.; Dong, Y.; Dong, X.; Cerneaux, S.; Hampshire, S.; Cao, J.; Zhu, L.; Zhu, Z.; Liu, J. A low-cost alumina-mullite composite hollow fiber ceramic membrane fabricated via phase-inversion and sintering method. J. Eur. Ceram. Soc. 2016, 36, 2057-2066. [CrossRef]

38. Li, L.Y.; Tazaki, K.; Lai, R.; Shiraki, K.; Asada, R.; Watanabe, H.; Chen, M. Treatment of acid rock drainage by clinoptilolite-Adsorptivity and structural stability for different $\mathrm{pH}$ environments. Appl. Clay Sci. 2008, 39, 1-9. [CrossRef]

39. Moradi, M.; Karimzadeh, R.; Moosavi, E.S. Modified and ion exchanged clinoptilolite for the adsorptive removal of sulfur compounds in a model fuel: New adsorbents for desulfurization. Fuel 2018, 217, 467-477. [CrossRef]

40. Jamalzadeh, Z.; Haghighi, M.; Asgari, N. Synthesis, physicochemical characterizations and catalytic performance of $\mathrm{Pd} /$ carbon-zeolite and $\mathrm{Pd} /$ carbon-CeO2 nanocatalysts used for total oxidation of xylene at low temperatures. Front. Environ. Sci. Eng. 2013, 7, 365-381. [CrossRef]

41. Amereh, M.; Haghighi, M.; Estifaee, P. The potential use of HNO3-treated clinoptilolite in the preparation of $\mathrm{Pt} / \mathrm{CeO} 2-\mathrm{Clinoptilolite} \mathrm{nanostructured} \mathrm{catalyst} \mathrm{used} \mathrm{in} \mathrm{toluene} \mathrm{abatement} \mathrm{from} \mathrm{waste} \mathrm{gas} \mathrm{stream} \mathrm{at} \mathrm{low}$ temperature. Arab. J. Chem. 2018, 11, 81-90. [CrossRef]

42. Silva, M.C.; Lira, H.D.; Lima, R.D.; Freitas, N.L. Effect of Sintering Temperature on Membranes Manufactured with Clays for Textile Effluent Treatment. Adv. Mater. Sci. Eng. 2015, 2015, 7. [CrossRef]

43. Abdullah, N.; Rahman, M.A.; Othman, M.H.D.; Ismail, A.F.; Jaafar, J.; Aziz, A.A. Preparation and characterization of self-cleaning alumina hollow fiber membrane using the phase inversion and sintering technique. Ceram. Int. 2016, 42, 12312-12322. [CrossRef]

44. Hubadillah, S.K.; Othman, M.H.D.; Ismail, A.F.; Rahman, M.A.; Jaafar, J.; Iwamoto, Y.; Honda, S.; Dzahir, M.I.H.M.; Yusop, M.Z.M. Fabrication of low cost, green silica based ceramic hollow fibre membrane prepared from waste rice husk for water filtration application. Ceram. Int. 2018, 44, 10498-10509. [CrossRef]

45. Othman, N.H.; Wu, Z.; Li, K. A micro-structured La0.6Sr0.4Co0.2Fe0.8O3- $\delta$ hollow fibre membrane reactor for oxidative coupling of methane. J. Membr. Sci. 2014, 468, 31-41. [CrossRef]

46. Abdullah, N.; Rahman, M.A.; Dzarfan Othman, M.H.; Jaafar, J.; Aziz, A.A. Preparation, characterizations and performance evaluations of alumina hollow fiber membrane incorporated with UiO-66 particles for humic acid removal. J. Membr. Sci. 2018, 563, 162-174. [CrossRef]

47. Honda, S.; Ogihara, Y.; Hashimoto, S.; Iwamoto, Y. Thermal Shock Properties of Porous Alumina for Support Carrier of Hydrogen Membrane Materials. Adv. Bioceram. Porous Ceram. III 2010, 31, 127-137. [CrossRef]

48. Mohammadi, F.; Mohammadi, T. Optimal conditions of porous ceramic membrane synthesis based on alkali activated blast furnace slag using Taguchi method. Ceram. Int. 2017, 43, 14369-14379. [CrossRef]

49. Foo, K.Y.; Lee, L.K.; Hameed, B.H. Preparation of tamarind fruit seed activated carbon by microwave heating for the adsorptive treatment of landfill leachate: A laboratory column evaluation. Bioresour. Technol. 2013, 133, 599-605. [CrossRef]

50. Hu, Y.-N.; Wang, H.-Y.; Cao, G.-P.; Meng, C.; Yuan, W.-K. The adsorption of toluenediamine from the wastewater by activated carbon in batch and fixed bed systems. Desalination 2011, 279, 54-60. [CrossRef]

51. Zhou, L.; Qu, Z.G.; Chen, L.; Tao, W.Q. Lattice Boltzmann simulation of gas-solid adsorption processes at pore scale level. J. Comput. Phys. 2015, 300, 800-813. [CrossRef]

52. Adam, M.R.; Othman, M.H.D.; Abu Samah, R.; Puteh, M.H.; Ismail, A.F.; Mustafa, A.; Rahman, M.A.; Jaafar, J. Current trends and future prospects of ammonia removal in wastewater: A comprehensive review on adsorptive membrane development. Sep. Purif. Technol. 2019, 213, 114-132. [CrossRef]

53. Liu, C.-H.; Lo, K.V. Ammonia removal from composting leachate using zeolite. I. Characterization of the zeolite. J. Environ. Sci. Health Part A 2001, 36, 1671-1688. [CrossRef]

54. Wang, Y.; Liu, S.; Xu, Z.; Han, T.; Chuan, S.; Zhu, T. Ammonia removal from leachate solution using natural Chinese clinoptilolite. J. Hazard. Mater. 2006, 136, 735-740. [CrossRef] [PubMed]

55. Wang, Y.F.; Lin, F.; Pang, W.Q. Ammonium exchange in aqueous solution using Chinese natural clinoptilolite and modified zeolite. J. Hazard. Mater. 2007, 142, 160-164. [CrossRef] [PubMed]

56. Rožić, M.; Cerjan-Stefanović, Š.; Kurajica, S.; Vančina, V.; Hodžić, E. Ammoniacal nitrogen removal from water by treatment with clays and zeolites. Water Res. 2000, 34, 3675-3681. [CrossRef]

57. Farkas, A.; Rozic, M.; Barbaric-Mikocevic, Z. Ammonium exchange in leakage waters of waste dumps using natural zeolite from the Krapina region, Croatia. J. Hazard. Mater. 2005, 117, 25-33. [CrossRef] 
58. Ashrafizadeh, S.N.; Khorasani, Z.; Gorjiara, M. Ammonia Removal from Aqueous Solutions by Iranian Natural Zeolite. Sep. Sci. Technol. 2008, 43, 960-978. [CrossRef]

59. Weatherley, L.R.; Miladinovic, N.D. Comparison of the ion exchange uptake of ammonium ion onto New Zealand clinoptilolite and mordenite. Water Res. 2004, 38, 4305-4312. [CrossRef]

60. Karadag, D.; Koc, Y.; Turan, M.; Armagan, B. Removal of ammonium ion from aqueous solution using natural Turkish clinoptilolite. J. Hazard. Mater. 2006, 136, 604-609. [CrossRef]

61. Guo, X.; Zeng, L.; Li, X.; Park, H.S. Removal of Ammonium from RO Permeate of Anaerobically Digested Wastewater by Natural Zeolite. Sep. Sci. Technol. 2007, 42, 3169-3185. [CrossRef]

62. Hubadillah, S.K.; Othman, M.H.D.; Ismail, A.F.; Rahman, M.A.; Jaafar, J. A low cost hydrophobic kaolin hollow fiber membrane (h-KHFM) for arsenic removal from aqueous solution via direct contact membrane distillation. Sep. Purif. Technol. 2019, 214, 31-39. [CrossRef]

63. Zhu, Y.; Chen, D. Novel clay-based nanofibrous membranes for effective oil/water emulsion separation. Ceram. Int. 2017, 43, 9465-9471. [CrossRef]

64. Foorginezhad, S.; Zerafat, M. Microfiltration of cationic dyes using nano-clay membranes. Ceram. Int. 2017, 43, 15146-15159. [CrossRef]

65. Harabi, A.; Guechi, A.; Condom, S. Production of supports and filtration membranes from Algerian kaolin and limestone. Procedia Eng. 2012, 33, 220-224. [CrossRef]

66. Jana, S.; Purkait, M.; Mohanty, K. Preparation and characterization of low-cost ceramic microfiltration membranes for the removal of chromate from aqueous solutions. Appl. Clay Sci. 2010, 47, 317-324. [CrossRef]

67. Chen, M.; Zhu, L.; Dong, Y.; Li, L.; Liu, J. Waste-to-Resource Strategy To Fabricate Highly Porous Whisker-Structured Mullite Ceramic Membrane for Simulated Oil-in-Water Emulsion Wastewater Treatment. ACS Sustain. Chem. Eng. 2016, 4, 2098-2106. [CrossRef]

68. Harabi, A.; Boudaira, B.; Bouzerara, F.; Foughali, L.; Zenikheri, F.; Guechi, A.; Ghouil, B.; Condom, S. Porous ceramic supports for membranes prepared from kaolin (DD3) and calcite mixtures. Acta Phys. Pol. A 2015, 127, 1164-1166. [CrossRef]

69. de Oliveira Henriques, J.D.; Pedrassani, M.W.; Klitzke, W.; Mariano, A.B.; Vargas, J.V.C.; Vieira, R.B. Thermal treatment of clay-based ceramic membranes for microfiltration of Acutodesmus obliquus. Appl. Clay Sci. 2017, 150, 217-224. [CrossRef]

(C) 2020 by the authors. Licensee MDPI, Basel, Switzerland. This article is an open access article distributed under the terms and conditions of the Creative Commons Attribution (CC BY) license (http://creativecommons.org/licenses/by/4.0/). 